\title{
Design and Implementation of a Tri-Band Miniaturized Planar Inverted-F Antenna with Double Resonator for GPS Application
}

\author{
Amira Bousselmi \\ Faculty of Sciences of Tunis \\ Tunis El Manar University \\ El Manar, Tunisia \\ bousselmiamira@gmail.com
}

\author{
Ali Gharsallah \\ Faculty of Sciences of Tunis \\ Tunis El Manar University \\ El Manar, Tunisia \\ ali.gharsallah@fst.utm.tn
}

\author{
Tan Phu Vuong \\ Institute of Microelectronics \\ Electromagnetism and Photonics \\ Grenoble, France \\ tanphu.vuong@gmail.com
}

\begin{abstract}
In this paper, a new planar inverted-F antenna is presented for GNSS applications and the DCS band. The proposed antenna structure is based on capacitive slots that achieve multiband behavior. The antenna has two resonators of dimensions $(31 \mathrm{~mm} \times 17 \mathrm{~mm} \times 0.35 \mathrm{~mm})$ and $(20.5 \mathrm{~mm} \times 17.5 \mathrm{~mm} \times$ $0.35 \mathrm{~mm})$, a ground plane $(60 \mathrm{~mm} \times 17.5 \mathrm{~mm} \times 0.35 \mathrm{~mm})$ and $6.5 \mathrm{~mm}$ height. A prototype was implemented and good agreement was noticed between the simulation and test results, indicating three resonant frequencies, namely $1.176 \mathrm{GHz}, 1.8 \mathrm{GHz}$ and $2.8 \mathrm{GHz}$. Radiation characteristics and diversity performance of the proposed structure is presented with detail.
\end{abstract}

Keywords-planar inverted-f antenna (PIFA); multi-band; GNSS; return loss; bandwidth

\section{INTRODUCTION}

Multi-band antennas have been widely used for new generation mobile communications, such as DCS1800, PCS1900, UMTS, WiMAX and Bluetooth [1, 2]. Global positioning system (GPS) applications have become very popular due to the fast advances in electronic technology, while their addition to handheld devices increases their antenna versatility [3]. The design of novel components with compact size and multi band operation has attracted interest, for its outstanding advantages [4]. Miniaturized components allow their integration in compact devices, resulting in small and lightweight portable terminals. Moreover, the cost of electronic circuits is gradually decreasing, which is a requirement for new and accessible tools. Finally, the integration of GPS band along with other wireless communication bands is also required in order to avoid an additional antenna $[5,6]$. The Planar Inverted-F Antenna (PIFA) could be a promising structure for new wireless communication systems and it has been widely used as an internal antenna in commercial applications [7-13]. In [10], a quad-band PIFA antenna with two radiating elements has been proposed. The radiating elements consist of two PIFA structures constituted by a meandered line and a folded patch connected with interdigitated capacitive strips. In [12], a compact dual-band PIFA antenna working in both Digital Video Broadcasting-Terrestrial and Wireless Local Area Network IEEE $802.11 \mathrm{~b} / \mathrm{g}$ frequency bands has been proposed. This structure was designed to be integrated on a monitor- equipped device. On [8] a dual band platform-free antenna for the 5G MIMO application of mobile devices was investigated [14]. The antenna was designed by adding a vertical metallic patch to the PIFA and setting another PIFA to feed the antenna by coupling.

The PIFA antenna proposed in this paper is designed to exhibit reduced size with respect to these works. The structure consists of nested PIFAs that initially operate at the DCS and GPS bands. Moreover, a juxtaposition technique was employed to add a second resonator between the ground plane and the patch loaded by the U-slot. Therefore, a new resonance at $2.8 \mathrm{GHz}$ appeared and multi-band behavior was achieved. A parametric study was carried out allowing a significant reduction in the size of the antenna. The proposed design was implemented, tested and good agreement between the simulation and the prototype test results was obtained.

\section{MULTI-BAND PIFA ANTENNA}

The geometry of the proposed multiband PIFA structure is exhibited in Figure 1. Its components were built from $0.35 \mathrm{~mm}$ thick copper substrate. The first design was composed of two layers. The first layer was a $(60 \times 17.5 \times 0.35 \mathrm{~mm})$ rectangular ground plane, corresponding to the dimensions of a typical mobile device. The second layer consists of a $(20.5 \times 17.5 \times 0.35 \mathrm{~mm})$ rectangular patch. The radiation is occurring through a graved by a radiating U-slot as shown in Figure 1(b). A shorting sheet, $10.5 \mathrm{~mm}$ wide, was placed between the resonator and the ground plane, in order to achieve the appropriate matching at the various operating bands of the antenna. This sheet was positioned $2 \mathrm{~mm}$ away from the feeding probe and was optimally located at the edge of the structure. The dimensions of the U-slot are illustrated in Table I. A coaxial cable was attached in position $(\mathrm{x}, \mathrm{y})=(10 \mathrm{~mm}, 2 \mathrm{~mm})$ to excite the antenna. This location was selected in order to obtain good matching results. The proposed antenna was designed to operate at the L5-GPS band, by optimizing the dimensions of the patch from (1) [6]:

$$
f=C / 4(L+W)
$$


The dimensions of the radiating U-slot were optimized to cover the DCS band. In (1), C is the speed of light, $L$ and $W$ are the length and width of the top plate respectively, and $f$ is the center frequency of the antenna.

(a)
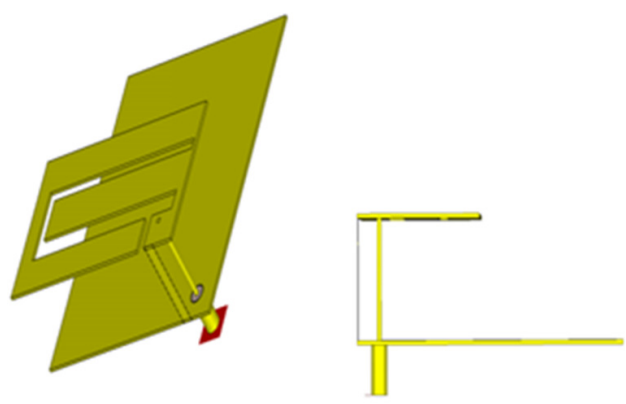

(b)

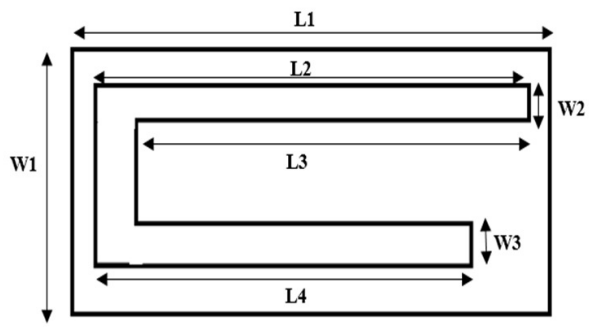

Fig. 1. (a) Dual band antenna, (b) detailed dimensions of the U-Slot

TABLE I. DIMENSIONS OF U SLOT

\begin{tabular}{|c|c|}
\hline Parameters & Values (mm) \\
\hline $\boldsymbol{L 1}$ & 31 \\
\hline $\boldsymbol{L} \mathbf{2}$ & 28 \\
\hline $\boldsymbol{L} 3$ & 26.7 \\
\hline $\boldsymbol{L} 4$ & 24.5 \\
\hline $\boldsymbol{W} \mathbf{1}$ & 17 \\
\hline $\boldsymbol{W} \mathbf{W}$ & 1.3 \\
\hline $\boldsymbol{W}$ & 2.3 \\
\hline
\end{tabular}

In order to further improve the performance of the proposed design and minimize its size, the juxtaposition technique was used by adding a second resonator between the two layers that compose the structure as shown in Figure 2.
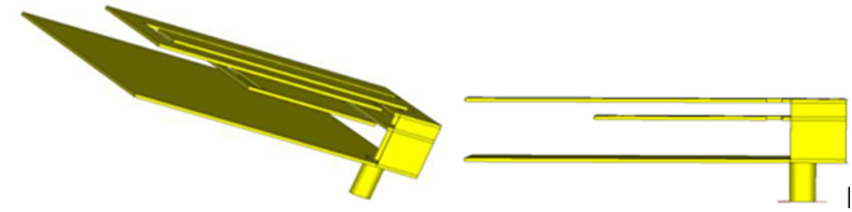

Fig. 2. The proposed antenna with two resonators

CST Microwave Studio simulation software was used in order to optimize all the geometrical parameters of the proposed antenna and obtain the far-field radiation patterns. In order to understand the effect of each resonator, the simulation S11 results for two prototypes were compared, as shown in Figure 3. It can be noticed that the first antenna has two resonance frequencies. The first one is allocated at $1176 \mathrm{MHz}$ while the second is at $1800 \mathrm{MHz}$. Adding the second resonator, a third resonance appeared around the frequency of $2.8 \mathrm{GHz}$. The radiation performance of the proposed dual band PIFA antenna is determined by two important factors: the width and the height of the shape slot and the length and the width of the antenna. In order to understand the influence of each element in the performance of the new structure, a parametric study was conducted to optimize the distance $H$ given between the new and the old resonator. Figure 4 shows the variation of the frequency as a function of high $H$. It was noticed that with increasing $H$, the two resonance frequencies increase and the third one decreases. Thus, parameter $H$ has an important effect on the antenna resonance. The optimized dimensions, through the parametric study, are exhibited in Table I.

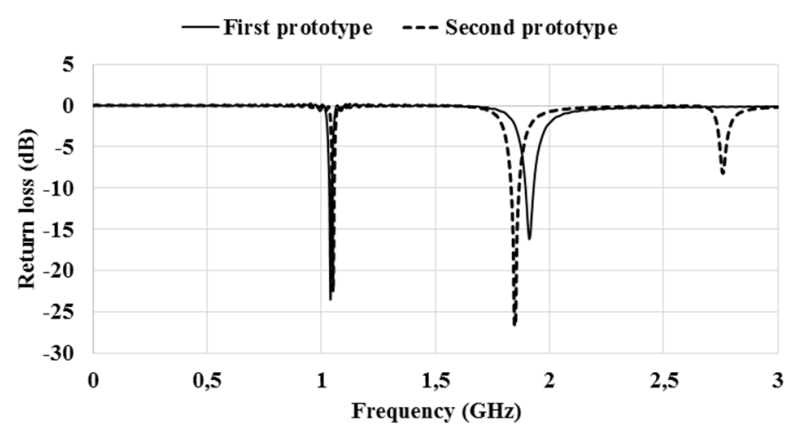

Fig. 3. Simulated return loss of the proposed antenna

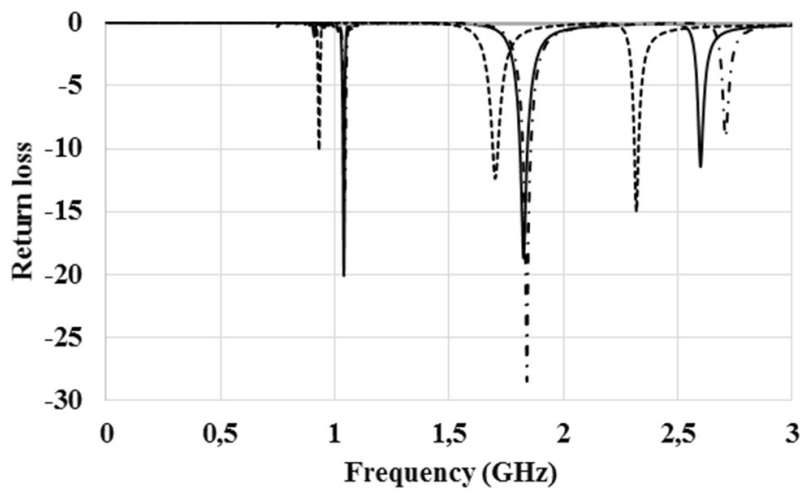

Fig. 4. Variation of the reflection coefficient with frequency of the proposed antenna for various $h$ values

\section{EXPERIMENTAL VALIDATION}

A prototype of the multi-band PIFA antenna was implemented in order to verify the simulation results. The top and bottom views of the prototype are exhibited in Figure 5. The design has the disadvantage of being very difficult to manufacture and solder. Another drawback resides in the sensitivity of the antenna with respect to mounting dimensions, hence the difficulty to be precise at inter-levels. The experimental part of this study was conducted at the Institute of Microelectronics Electromagnetism and Photonics (IMEPLAHC).
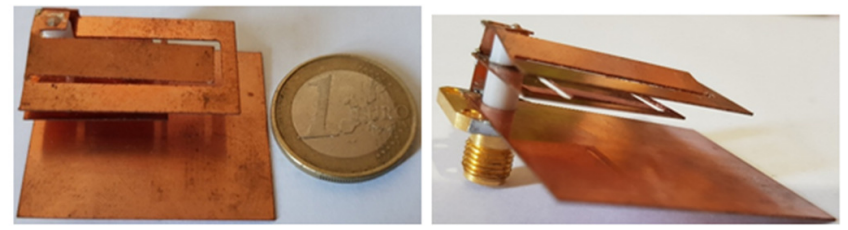

Fig. 5. The prototype of the multi-band antenna 


\section{A. S-Parameters}

The S-parameter testing of the prototype was carried out using a vector network analyzer as shown in Figure 6.

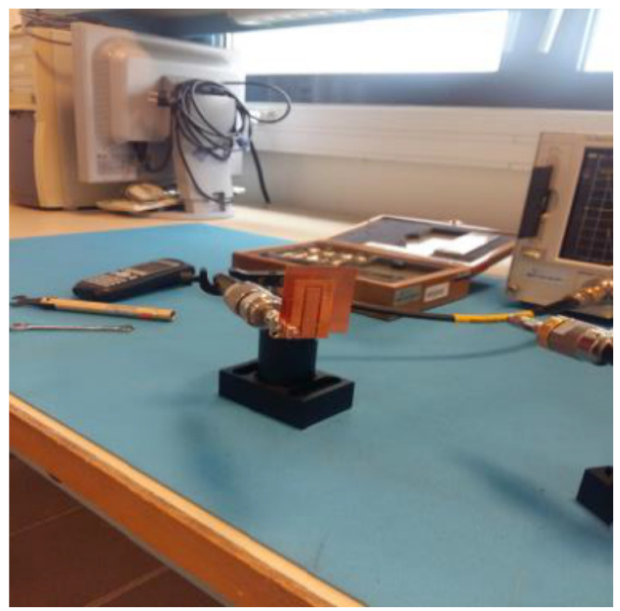

Fig. 6. The antenna in S-parameter testing

Figure 7 displays the return loss results of both the prototype and the CST simulation tests, showing good agreement. It is noted that by adding the second resonator $\mathrm{U}$ slot, a third resonant frequency appeared. The first resonance frequency is located at $1.176 \mathrm{GHz}$ with $-14.27 \mathrm{~dB}$ matching level and the second is located at $1.8 \mathrm{GHz}$ with matching level around $-34.3 \mathrm{~dB}$. The new resonance frequency is located at $2.8 \mathrm{GHz}$ and with $-11 \mathrm{~dB}$ impedance matching. The bandwidth at $-10 \mathrm{~dB}$ covers the bands: $1.164-1.18 \mathrm{GHz}, 1.78-1.82 \mathrm{GHz}$ and 2.79-2.81GHz.

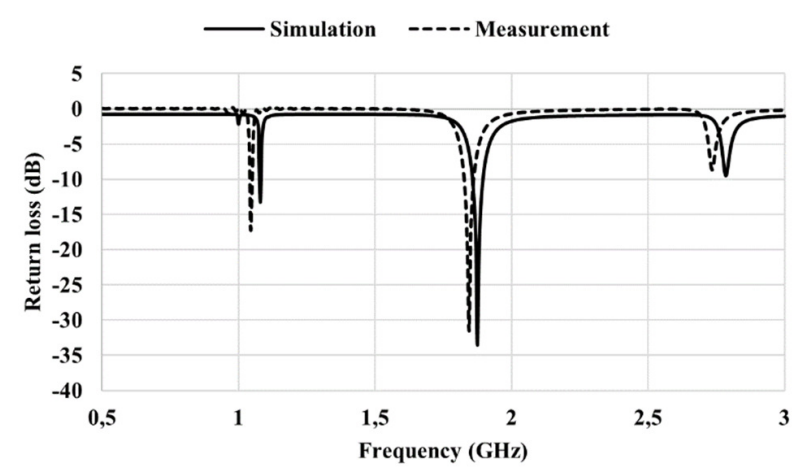

Fig. 7. Simulated and measured reflection coefficient:

\section{B. Radiation patterns}

The radiation patterns of the prototype multi-band PIFA antenna were tested in an anechoic chamber, within the antenna system operating bands, as shown in Figure 8. The simulation results of the proposed antenna's 3-D gain at the resonant frequencies are shown in Figure 9. It is observed that the gain for the first resonance $(1.176 \mathrm{GHz})$ is $1.75 \mathrm{~dB}$, for the second resonance $(1.8 \mathrm{GHz})$ is $1.92 \mathrm{~dB}$, and finally for the last resonance $(2.8 \mathrm{GHz})$ the gain is maximized at $3.2 \mathrm{~dB}$. It is clearly obvious that the test results reasonably correspond to the simulation. The radiation efficiency comparison between simulation and test results is shown in Figure 10. Results show that the antenna has good radiation efficiency, at all operating bands, with an average of $70 \%$. More details about the simulation and the prototype results of the proposed triple band PIFA antenna are presented in Table II.

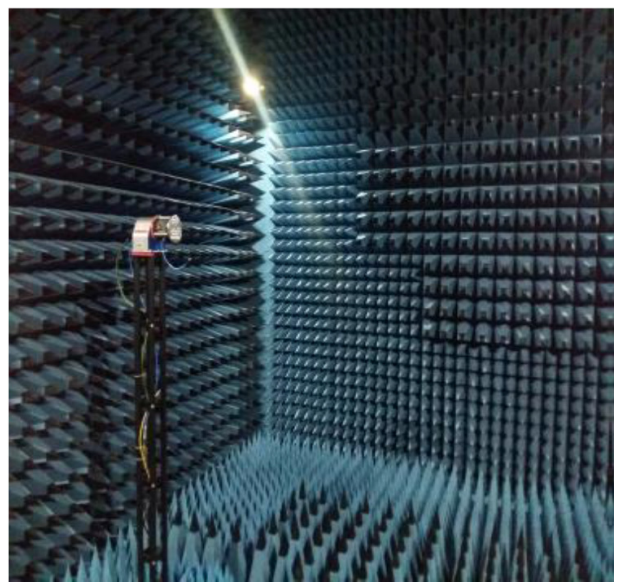

Fig. 8. The proposed antenna prototype during testing in the anechoic chamber
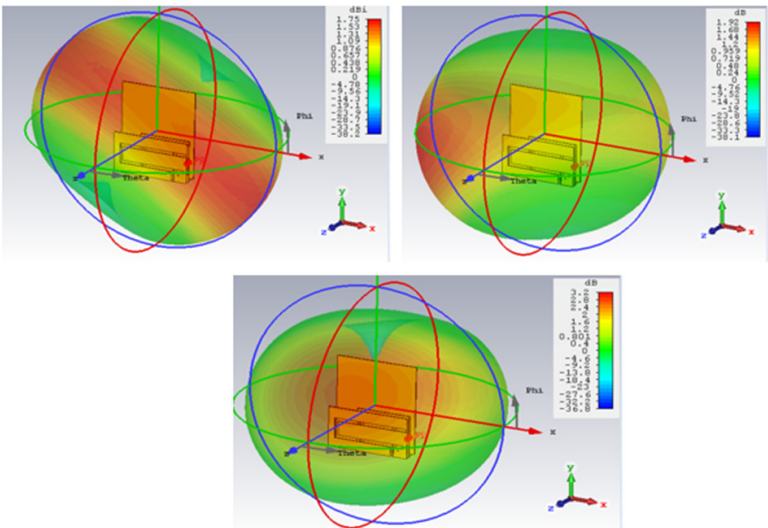

Fig. 9. Simulated 3-D far-field total radiation patterns at (a) $1.176 \mathrm{GHz}$ (b) $1.8 \mathrm{GHz}$, (c) $2.8 \mathrm{GHz}$

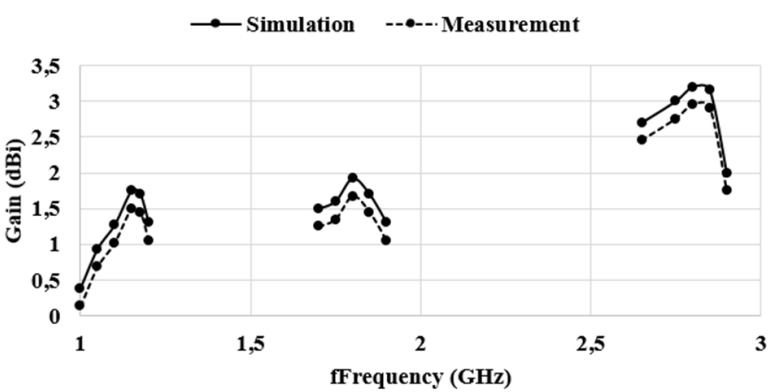

Fig. 10. The results for the measured and simulated gain

Table III compares the results of this work with others in the literature. The comparison takes into account the dimensions of the antenna, concluding that the proposed antenna is much smaller. 
TABLE II. SIMULATION AND PROTOTYPE RESULTS

\begin{tabular}{|c|c|c|c|}
\hline \multicolumn{2}{|c|}{} & Simulation & Prototype \\
\hline First band & Resonant frequency(GHz) & 1.176 & 1.17 \\
(Galileo, & Bandwidth (GHz) & 0.16 & 0.19 \\
GPS) & Matching level (dB) & -14.27 & -22 \\
& Gain (dB) & 1.75 & 1.65 \\
\hline \multirow{2}{*}{ Second } & Resonant frequency(GHz) & 1.8 & 1.75 \\
band & Bandwidth (GHz) & 0.40 & 0.50 \\
(DCS) & Matching level (dB) & -34.3 & -35.1 \\
& Gain (dB) & 1.92 & 1.8 \\
\hline \multirow{2}{*}{ Third } & Resonant frequency (GHz) & 2.8 & 2.77 \\
band & Bandwidth (GHz) & 0.20 & 0.20 \\
(2.8GHz) & Matching level (dB) & -12.02 & -18.02 \\
& Gain (dB) & 3.2 & 2.1 \\
\hline
\end{tabular}

TABLE III. COMPARISON OF THE PROPOSED WITH OTHER ANTENNAS

\begin{tabular}{|c|c|c|c|}
\hline Ref & Band & Antenna dimensions & Volume \\
\hline [7] & $\begin{array}{l}\text { GSM band } \\
\text { DCS band } \\
\text { Bluetooth } \\
\text { WLAN } \\
\end{array}$ & $100 \times 60 \times 8$ & 48000 \\
\hline [8] & $\begin{array}{l}2.6 \mathrm{GHz} \\
5.0 \mathrm{GHz}\end{array}$ & $136 \times 68 \times 5$ & 46240 \\
\hline [9] & $\begin{array}{l}1.9 G H z \\
2.1 G H z\end{array}$ & $140 \times 60.5 \times 10$ & 84700 \\
\hline$[10]$ & $\begin{array}{c}746-787 \mathrm{MHz}, \\
1850-1990 \mathrm{MHz}, \\
1920-2170 \mathrm{MHz}, \\
3600-3700 \mathrm{MHz}\end{array}$ & $60 \times 100 \times 5$ & 30000 \\
\hline [11] & $\begin{array}{c}2 \mathrm{GHz} \\
2.6 \mathrm{GHz}\end{array}$ & $44 \times 100 \times 11.5$ & 50600 \\
\hline [12] & $\begin{array}{c}470-862 \mathrm{MHz} \\
2400-2484 \mathrm{MHz}\end{array}$ & $217 \times 12 \times 8$ & 20832 \\
\hline [13] & $\begin{array}{c}\text { GPS L1 } \\
\text { Wi-Fi/LTE2500 } \\
\text { WiMAX } \\
\text { HIPERLAN1 }\end{array}$ & $25 \times 10 \times 5.8$ & 2400 \\
\hline [8] & $\begin{array}{l}\text { WIFI } \\
\text { GPS }\end{array}$ & $20 \times 15 \times 8$ & 2400 \\
\hline Proposed & $\begin{array}{c}1.176 \mathrm{GHz} \\
1.8 \mathrm{GHz} \\
2.8 \mathrm{GHz} \\
\end{array}$ & $20.5 \times 17 \times 6.5$ & 2265.25 \\
\hline
\end{tabular}

\section{CONCLUSION}

This work presented a multiband miniaturized PIFA antenna, consisting of three elements. The antenna operates at the frequency bands of $1.164-1.18 \mathrm{GHz}, 1.78-1.82 \mathrm{GHz}$ and 2.79-2.81GHz, covering GPS and DCS applications. The proposed design is suitable for many portable devices, thanks to its low profile and small size and it can be used in handheld devices. A prototype of the proposed antenna was constructed and tested. The test results agree with those predicted by simulation.

\section{REFERENCES}

[1] T. Y. Wu, K. L. Wong, "On the impedance bandwidth of a planar inverted-F antenna for mobile handsets", Microwave and Optical Technology Letters, Vol. 32, pp. 249-251, 2002

[2] M. C. Huynh, W. Stutzman, "Ground plane effects on planar inverted-F antenna (PIFA) performance", IEE Proceedings-Microwaves, Antennas and Propagation, Vol. 150, No. 4, pp. 209-213, 2003

[3] Y. X. Guo, S. Tan, "New compact six-band internal antenna," IEEE Antennas and Wireless Propagation Letters, Vol. 3, pp. 295-297, 2004

[4] A. A. Serra, P. Nepa, G. Manara, R. Massini, "A low-profile linearly polarized 3D PIFA for handheld GPS terminals", IEEE Transactions on Antennas and Propagation, Vol. 58, No. 4, pp. 1060-1066, 2010
[5] K. Hirasawa, M. Haneishi, Analysis, design and measurement of small and low-profile antennas, Artech House, 1992

[6] D. M. Nashaat, H. A. Elsadek, H. Ghali, "Single feed compact quadband PIFA antenna for wireless communication applications", IEEE Transactions on Antennas and Propagation, Vol. 53, No. 8, pp. 26312635,2005

[7] D. Q. Liu, M. Zhang, H. J. Luo, H. L. Wen, J. Wang, "Dual-band platform-free PIFA for 5G MIMO application of mobile devices", IEEE Transactions on Antennas and Propagation, Vol. 66, No. 11, pp. 63286333, 2018

[8] B. R. Jackson, S. J. Boyes, "Radiation pattern-agile dual planar invertedF antenna", IEEE Antennas and Wireless Propagation Letters, Vol. 16, pp. 2090-2093, 2017

[9] M. K. Meshram, R. K. Animeh, A. T. Pimpale, N. K. Nikolova, “A novel quad-band diversity antenna for LTE and Wi-Fi applications with high isolation", IEEE Antennas and Wireless Propagation Letters, Vol. 60 , No. 9, pp. 4360-4371, 2012

[10] S. Vergerio, J. P. Rossi, P. Sabouroux, "A two-PIFA antenna systems for mobule phone at $2 \mathrm{GHz}$ with MIMO applications", 2006 First European Conference on Antennas and Propagation, Nice, France, November 610,2006

[11] R. Caso, A. D’Alessandro, A. A. Serra, P. Nepa, G. Manara, "A compact dual-band PIFA for DVB-T and WLAN applications", IEEE Transactions on Antennas and Propagation, Vol. 60, No. 4, pp. 20842087, 2012

[12] H. S. Singh, M. Agarwal, G. K. Pandey, M. K. Meshram, “A quad-band compact diversity antenna for GPS L1/WiFi/LTE2500/WiMAX/HIPERLAN1 applications", IEEE Antennas and Wireless Propagation Letters, Vol. 13, pp. 249-252, 2014

[13] A. Bousselmi, A. Gharsallah, T. Vuong, "A novel high-gain quad-band antenna with AMC metasurface for satellite positioning systems", Engineering, Technology \& Applied Science Research, Vol. 9, No. 5, pp. 4581-4585, 2019

[14] E. S. Ahmed, "Conformal band-notch UWB monopole antenna on finite cylindrical substrates", Engineering, Technology \& Applied Science Research, Vol. 3, No. 3, pp. 440-445, 2013 